\title{
IMMUNOGLOBULIN CLASSES OF ANTIBODIES IN THE SERA OF BUFFALOES INFECTED WITH TOXOCARA VITULORUM
}

\author{
S. T. FERNANDO, BIMBA T. SAMARASINGHE AND VIRANJANI K. \\ GUNAWARDENA \\ Faculty of Veterinary Medicine \& Animal Science, University of Peradeniya, Peradeniya, \\ Sri Lanka.
}

(Date of receipt : 14 June 1988)

(Date of acceptance : 17 August 1989)

\begin{abstract}
Serum samples of buffalo calves naturally infected with Toxocara vitulorum were fractionated by means of 'Sephadex' G-200 gel-filtration. On gel-filtration, the buffalo sera separated into three main peaks sometimes with two :minor peaks between peaks -1 and -2 as were those of other domestic animals. IgM and $\mathrm{X}_{2}$-macroglobulins were eluted mostly with the peak-1 and the trough following this peak. The IgG's were eluted largely with the peak-2 and the trough following this peak. On further fractionation the bulked and concentrated eluates of peak-2 resolved into two subclasses consisting of $\mathbf{I g G}_{2}$ and $\operatorname{IgG}_{1}$. The antibody activity of these classes was examined by the enzyme-linked immunosorbent, gel-diffusion, in vitro larval precipitin and passive cutaneous anaphylaxis techniques (ELISA, GPT, IVP, PCA). A phosphate buffered saline extract of infective $T$. vitulomm eggs was used as the antigen. The ELISA activity was distributed throughout the peaks -1 and -2 , the trough between these peaks and that following peak -2 . The GPT and IVP antibodies were present in the IgG ${ }_{1}$ and not in $\operatorname{IgG}_{2}$ the immunoglobulin subclasses constituting the peak-2. The PCA activity was confined largely to the ascending part of peak-1 in the sera collected during the prepatent and patent phases of the infection whereas this activity was mostly confined to two minor peaks preceding peak -2 in the sera collected from days 174 of birth but after the experimental infection with 50,000-100,000 infective eggs on day 160 .
\end{abstract}

\section{Introduction}

In the past decade a considerable amount of work has been done on the isolation and characterization of the serum immunoglobulins of bovidae. $3,4.15$ These studies have shown that in general the immunoglobulins of bovidae have features similar to those of man and other mammals. Three main classes of serum immunoglobulins namely IgM, IgG and IgA have been recognized in the bovidae. Furthermore studies have been made on the immunoglobulins of the Indian buffalo by means immunoelectrophoresis against rabbit antibuffalo serum ${ }^{16,17,18}$ and these studies have revealed that there were three main classes, namely, IgG, IgA and IgM in buffalo sera similar to those in cattle. But the identification of these immunoglobulins had been based mainly on the immunoelectrophoretic precipitation pattern, relative mobility, position and shape of the precipitin bands and not on the more reliable characteristics such as the elution pattern in column chromatography and precipitation studies with specific antisera prepared against the heavy chains or Fc fragments of the relevant immunoglobulins. An immunoglobulin class consists of two light and two heavy polypeptide chains and the light chains ( $k$ or 1 ) are shared by all the immunoglobulin 
classes whereas the heavy chains $\gamma, \alpha$ and $\mu$ of $\operatorname{IgG}, \operatorname{IgA}$ and $\operatorname{IgM}$ are specific for the classes. Thus a considerable amount of cross reactions could have occurred among these immunoglobulins. Further studies on the immunoglobulins of buffaloes, cows, sheep, goat, horse and man have shown that a considerable degree of cross reaction occurred among the immunoglobulins of these species. ${ }^{18}$

In general Toxocara vitulorum infection becomes patent about 21 days after birth and thus during this prepatent period a larval infection acquired by a calf from the milk of the dam matures in the intestines and eggs of $T$. vitulorum appear in the faeces from about the third week after birth. The patent phase lasts four to six weeks and at the end of this phase T. vitulorum egg counts in the faeces fall to almost zero levels. During this postpatent phase which follows the patent phase the calf is solidly immune to an acquired reinfection. In brief, a reinfection does not reach maturity in the host. During the postpatent phase some animals were infected experimentally with a single dose from 160 th day of birth. Thus in this study serum samples collected weekly from day 174 were examined also for their antibody activity.

\section{Materials and Methods}

\subsection{Sera}

Buffalo calves were bled for sera on day 0 (immediately after birth) before being fed with colostrum, and thereafter, the calves were allowed to remain with their dams. Subsequently the animals were bled on days 1 and 7 , and thereafter every week. The sera collected after overnight-clotting were centrifuged and stored at $-20^{\circ} \mathrm{C}$ until required for use.

\section{2 'Sephadex' G-200 gel-filtration}

This was carried out by upward flow in three (100 × $2.6 \mathrm{~cm}$ ) columns (Pharmacia Fine Chemicals, Sweden) connected in series. The flow rate was adjusted to $25 \mathrm{ml} / \mathrm{h}$ and phosphate buffered saline $\mathrm{pH} 7.2$ (PBS) was used in a continuous flow ${ }^{7}$ and the volume of the serum sample applied at each fractionation was $6 \mathrm{ml}$.

\subsection{Ion exchange chromatography}

This was carried out in DEAE-A-25 'Sephadex' (Pharmacia) in 0.056M Tris-hydrochloride buffer $\mathrm{pH} 8.6 .^{5}$. A Pharmacia column $25 \times 1.5 \mathrm{~cm}$ was packed with the resin to a height of $20 \mathrm{~cm}$ at a hydrostatic pressure of 37.5 $\mathrm{cm}$. The concentrated eluates from the peak-2 of 'Sephadex' gel-filtration (Figures 1 \& 2) were applied in a volume of $2.5 \mathrm{ml}$. The protein concentration of the samples applied was $10 \mathrm{mg} / \mathrm{ml}$. The flow rate of the column was adjusted to $24 \mathrm{ml} / \mathrm{h}$ and the column was washed with $120 \mathrm{ml}$ of the starting buffer to elute the first peak and thereafter the second buffer which was the starting buffer with $0.1 \mathrm{M}$ sodium chloride (Figure 6) was applied. 


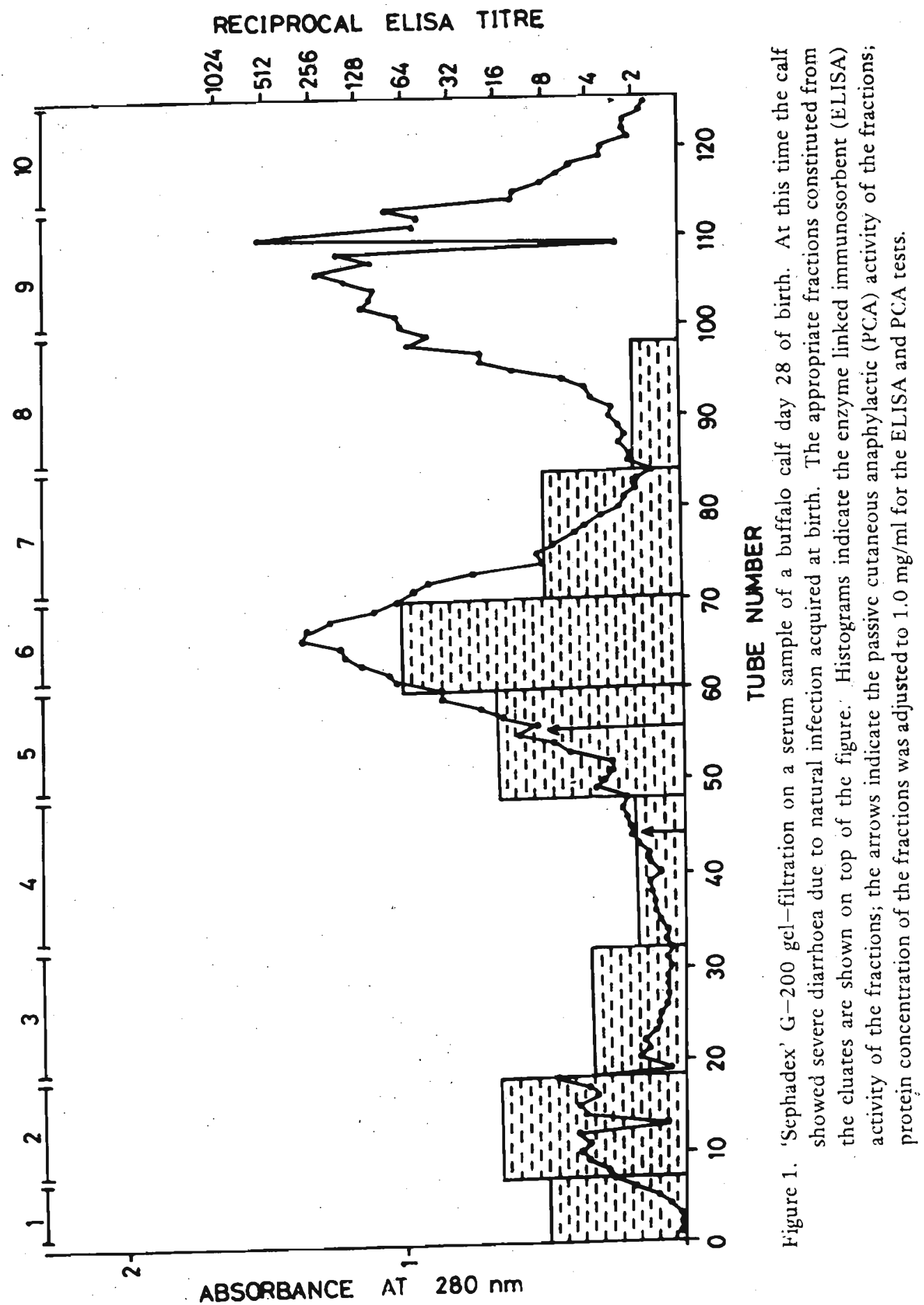




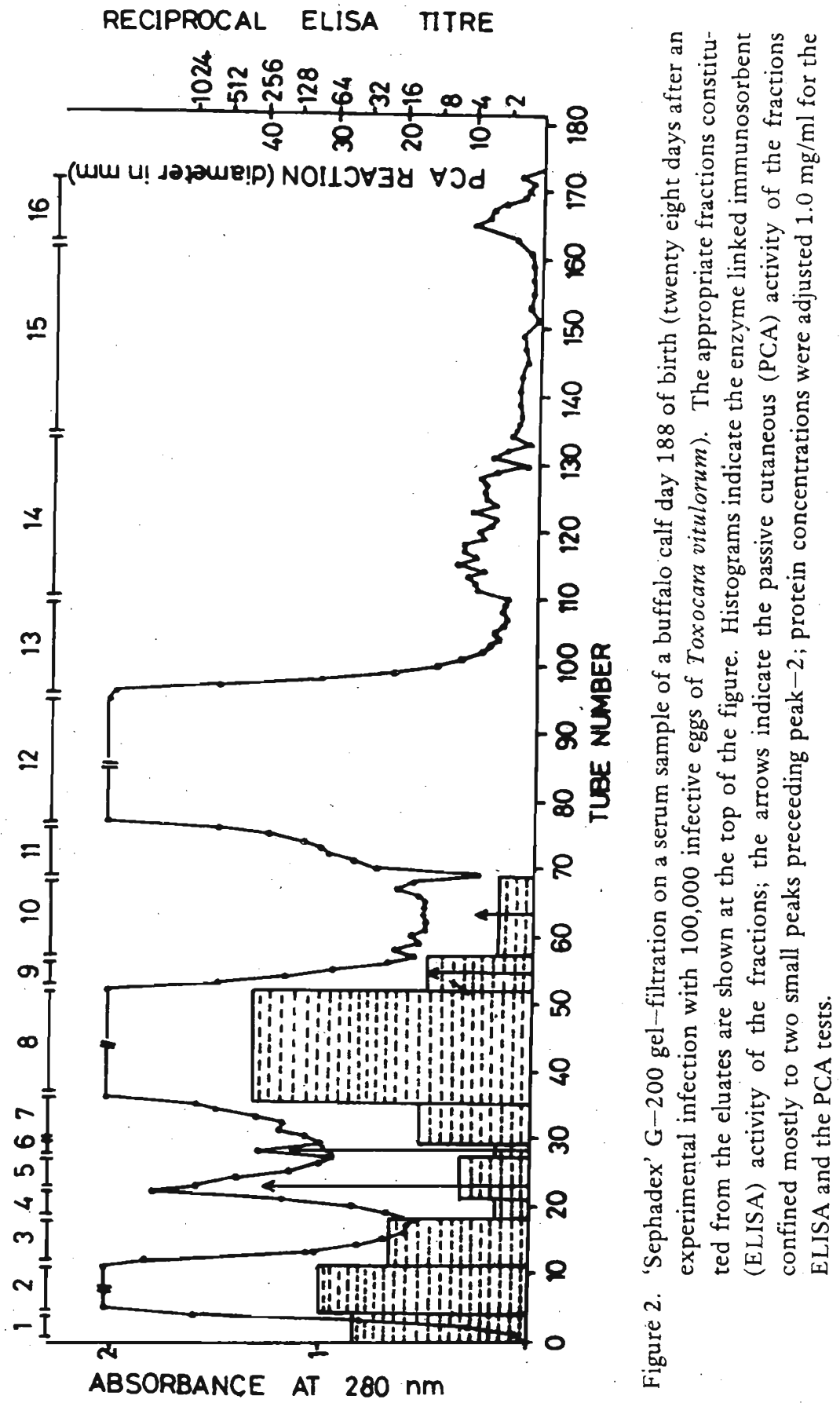




\subsection{Characterization of the fractions}

The eluates pooled from different parts of the chromatogram as indicated in the Figures 1 and 2 were concentrated by dialysis in polyethylene glycol M.W. 300,000 (Aquacide-III, Calbiochem, California). In the results fractions $(\mathrm{F})$ refer to the bulked and concentrated eluates constituting the appropriate parts of the chromatograms (Figures 1 and 2; marked on top of each figure). The numerals after the $F$ (suffixes) refer to the fraction number in the appropriate part of the chromatogram.

The elution pattern and the behaviour of the fractions in immunoelectrophoresis against the appropriate antisera were the main criteria used in identification.

\subsection{Antigen}

Extracts of embryonated T. vitulorum eggs (TVE) prepared with phosphate buffered saline $\mathrm{pH} 7.2$ (PBS) as described earlier ${ }^{8}$ for Toxocara canis was used as the antigen. The protein concentration of the antigen was determined by the Folin-Ciocalteau phenol reagent. ${ }^{20}$ Antigen solutions with $0.07 \mathrm{mg}$ and $1.0 \mathrm{mg}$ per $\mathrm{ml}$ in the appropriate buffers were used in the ELISA and the GPT reactions. The appropriate protein concentrations of the antigens required for the tests were determined by a series of preliminary titrations.

\subsection{Enzyme linked immunosorbent assay (ELISA)}

This technique was carried out in polyvinyl chloride microplates MIC- -6000 (Dynatech Laboratories) as described earlier. ${ }^{1}$

\subsection{Gel-diffusion precipitin (GPT) test}

The GPT was carried out in $1 \%$ agarose (type-IV, Sigma Laboratories, U.S.A.) in veronal buffer ${ }^{12,21}$ as described earlier. ${ }^{7}$

\subsection{In vitro larval precipitin test (IVP)}

The IVP was carried on all the fractions (Figures $1,2,6$ ) as described earlier. ${ }^{7}$

\subsection{Immunoelectrophoresis}

The immunoelectrophoresis was carried out in $1.0 \%$ agarose. ${ }^{14}$ The precipitin arcs corresponding to the separated globulins were developed with rabbit antibuffalo globulin serum prepared in the laboratory and with antibovine IgM heavy $(\mu), \operatorname{IgG}$ heavy $(\gamma)$ and light (K or l) and antihuman heavy $(\epsilon)$ chain specific rabbit IgG fractions (Cappel Laboratories, Cochranville, PA. 19330, U.S.A.). 


\subsection{Passive cutaneous anaphylaxis (PCA)}

The principles of the technique (PCA) were similar to those used by earlier workers. ${ }^{2,1} 3,24$

Since the skin of buffalo calves is darkly pigmented and the infection is endemic in buffalo calves the PCA tests could not be performed on them. Thus, these tests were carried out on four Ayreshire calves known to be free of helminth infection with the appropriate fractions from sera from four buffalo calves taken during the prepatent, patent, postpatent periods as well as after the experimental infections with eggs. The protein concentration of the fractions was adjusted to $1.0 \mathrm{mg}$ per $\mathrm{ml}$ in PBS and $0.5 \mathrm{ml}$ amounts of the fractions were injected intradermally into areas marked previously on the shaved abdomen of the animal. The sites of the injections were examined daily. Seventy two hours ${ }^{11}$ after the intradermal injections the animals were given 0.5 of $T$. vitulorum egg antigen intravenously followed immediately by $20 \mathrm{ml}$ of $0.5 \%$ Evans blue by the same route. The discrete blue patches which appeared within 20-30 minutes were measured in $\mathrm{mm}, 30 \mathrm{~min}$ after the injection of antigen and dye.

\subsection{Action of 2-mercaptoethanol}

Pooled concentrated fraction (protein $1.0 \mathrm{mg} / \mathrm{ml}$ ) from the ascending limb of the first peak of the 'Sephadex' G-200 gel-filtration sera was incubated with an equal volume of $2-$ mercaptoethanol $(0.2 \mathrm{M})$ at $37^{\circ} \mathrm{C}$ for one hour and then dialysed for three days in several changes of PBS containing $0.02 \mathrm{M}$ iodoacetamide in order to remove the excess 2-mercaptoethanol. The sample was thereafter concentrated by dialysis against polyethylene glycol.

The ascending limb of the peak-1 contained largely of IgM and presumably $\alpha_{2}-$ macroglobulin (Figure 4 ) and no other proteins. Therefore only the ascending limb of peak-1 was taken to ascertain the action of 2mercaptoethanol on the protein which reacted with the rabbit anti-IgM specific IgG fractions. The fraction (2) from peak-1 following that prepared from the ascending limb contained a minimum of 3-4 proteins (Figure 3). Therefore these fractions were not used for this test.

\section{Results}

\section{1 'Sephadex' G-200 gel-filtration}

Examples of the gel-filtration chromatogram profiles of buffalo sera are shown (Figures 1 and 2). In the same figures the distribution of antibodies determined by ELISA and PCA is shown.

On 'Sephadex' gel-filtration buffalo calf serum in general separated into three main peaks. The sera collected after experimental infection 
revealed also two minor peaks between Peaks 1 and 2 (Figure 2). The concentrated fractions from the eluates constituting the ascending and descending limbs and summits of the peaks were subjected to immunoelectrophoresis and the precipitin bands were developed against rabbit antibuffalo globulin sera. The pattern of a representative reaction is shown (Figure 3).

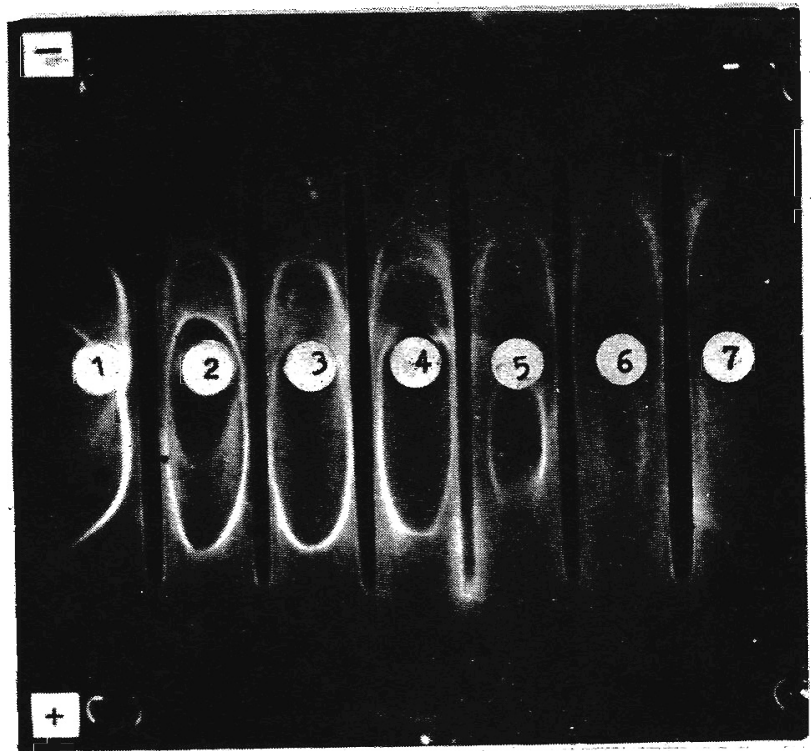

Figure 3. Immunoelectrophoretic precipitin pattern of the concentrated fractions prepared from the eluates from 'Sephadex' gel-filtration of a serum sample $(6 \mathrm{ml})$. Longitudinal troughs contained the rabbit antibuffalo globulin; the horizontal wells contained the concentrated fractions $(1-7)$ from Figure 1.

\subsection{Peak 1}

The fraction 1 from the ascending limb of peak-1 revealed two distinct bands one with the cathodal movement but commencing from the anodal side of the fraction well and the other band with the anodal movement commencing little distance away from the cathode side of the well but sometimes running through the well.

For more specific identifiçation of the protein in the fraction- 1 by immunoelectrophoresis, the precipitation arcs were developed also with rabbit antibovine IgM ( $\mu$-chain) specific IgG fractions. An example of a precipitation pattern developed is shown (Figure 4). A very strong precipitation arc similar to the band representing the protein which showed cathodal migration with fraction-1 was observed indicating that (1) it is an IgM (2) the serum IgM of cattle and buffalo origin show a strong cross reaction. The protein which showed an anodal type of migration is thought to be the $\alpha_{2}$ - macroglobulin and it did not react with the rabbit antibovine IgM specific serum. The neonatal calf serum did not react with rabbit anti bovine IgM ( $\mu$-chain) specific anti IgG. But it reacted with rabbit antibuffalo globulin serum. 


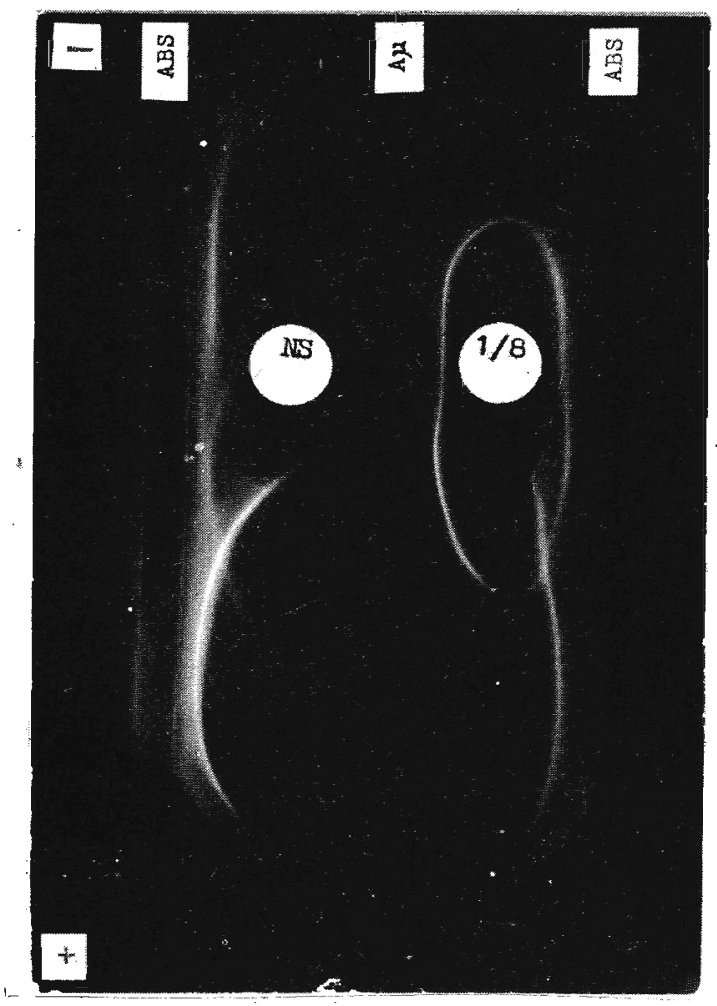

Figure 4. Immunoelectrophoresis on fraction-1 constituted from the eluates of the ascending limb of peak-1, Figure -1 and on a neonate whole serum sample of a buffalo calf before being fed with colostrum. NS, neonate buffalo calf serum; 1/8, Fraction-1 from the chromatogram (Figure-1); A $\mu$, rabbit antibovine IgM ( $\mu$-chain specific); ABS, rabbit antibuffalo globulin sera.

To ascertain the pattern of elution of IgM, protein fractions on 'Sephadex' gel-filtration, agarose-gel diffusion precipitin tests were carried out on the fractions from peaks 1 and 2 against antibovine IgM. It was evident that most of the IgM is eluted with the first peak and traces with the trough following this peak.

\subsection{Peak 2}

The fractions constituting the ascending and descending limbs, summit of this peak and part of the trough immediately following it consisted largely of IgG's. Usually the bands representing the IgG's were faint and appeared to consist of a minimum of two lines which, in general, showed a marked cathodal migration (Figure 3 ). 
A comparison of the buffalo serum proteins eluted in ascending limb of a peak -1 and the summit of a peak-2 was made with those from the similar peaks eluted from a serum sample of a calf from a 'Sephadex' G-200 gel-filtration. An example of an immunoelectrophoresis precipitin pattern of these apparently comparable fractions is shown (Figure 5). The bovine and buffalo fractions representing the corresponding parts of the chromatogram showed a similar type of mobility and precipitin pattern.

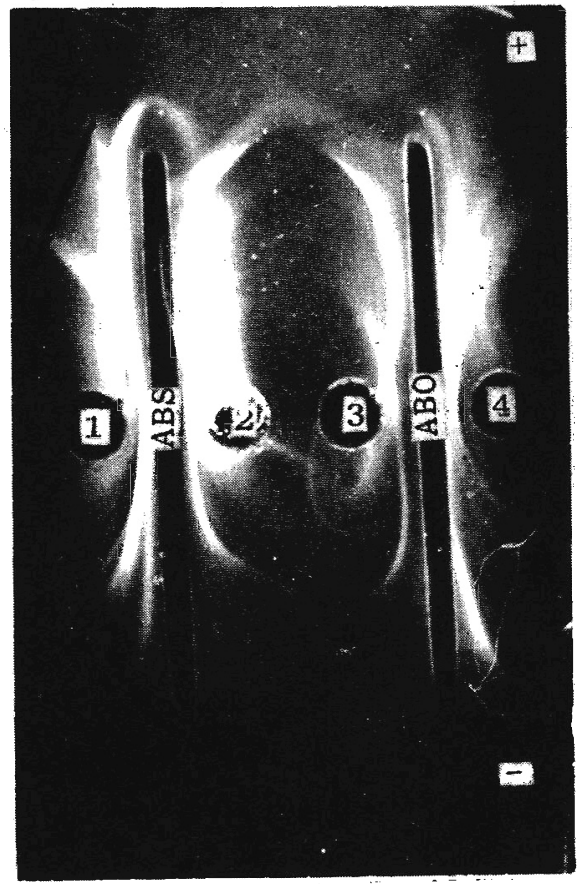

Figure 5. Immunoelectrophoresis on the bovine and buffalo whole sera and their concentrated fractions prepared from the eluates of the ascending limbs of 'Sephadex' G-200 gel-filtration. 1, a whole bovine serum sample; 2 , fraction-1 constituted from the peak-1; 3, fraction-1 from G-200 gel-filtration chromatography of a whole buffalo serum sample; 4 , whole buffalo serum sample. Rabbit antibovine ( $A B S$ ) and rabbit antibuffalo $(A B O)$ sera have been used to elicit the precipitin reaction.

\subsection{DEAE-A 25 Sephadex Chromatography}

In order to resolve the slow and fast IgG's $\left(\operatorname{IgG}_{1} ; \operatorname{IgG}_{2}\right)$ the eluates $(35-53)$ of peak-2 (Figure 2) were bulked and subjected to DEAE-A-25 'Sephadex ion exchange chromatography. A chromatogram profile of this type of separation is shown (Figure 6). The immunoelectrophoretic patterns of the concentrated fractions from the two peaks are shown (Figure 7). The pattern of the reaction indicated that the fractions from peak-1 (break through peak) consisted largely of the $\mathrm{IgG}_{2}$ the slow type and that from peak-2 consisted mainly of $\operatorname{IgG}_{1}$ the fast type. In addition the second peak contained also a minor fraction which requires confirmation. This might be the subclass $\mathrm{IgG}_{3}$. 


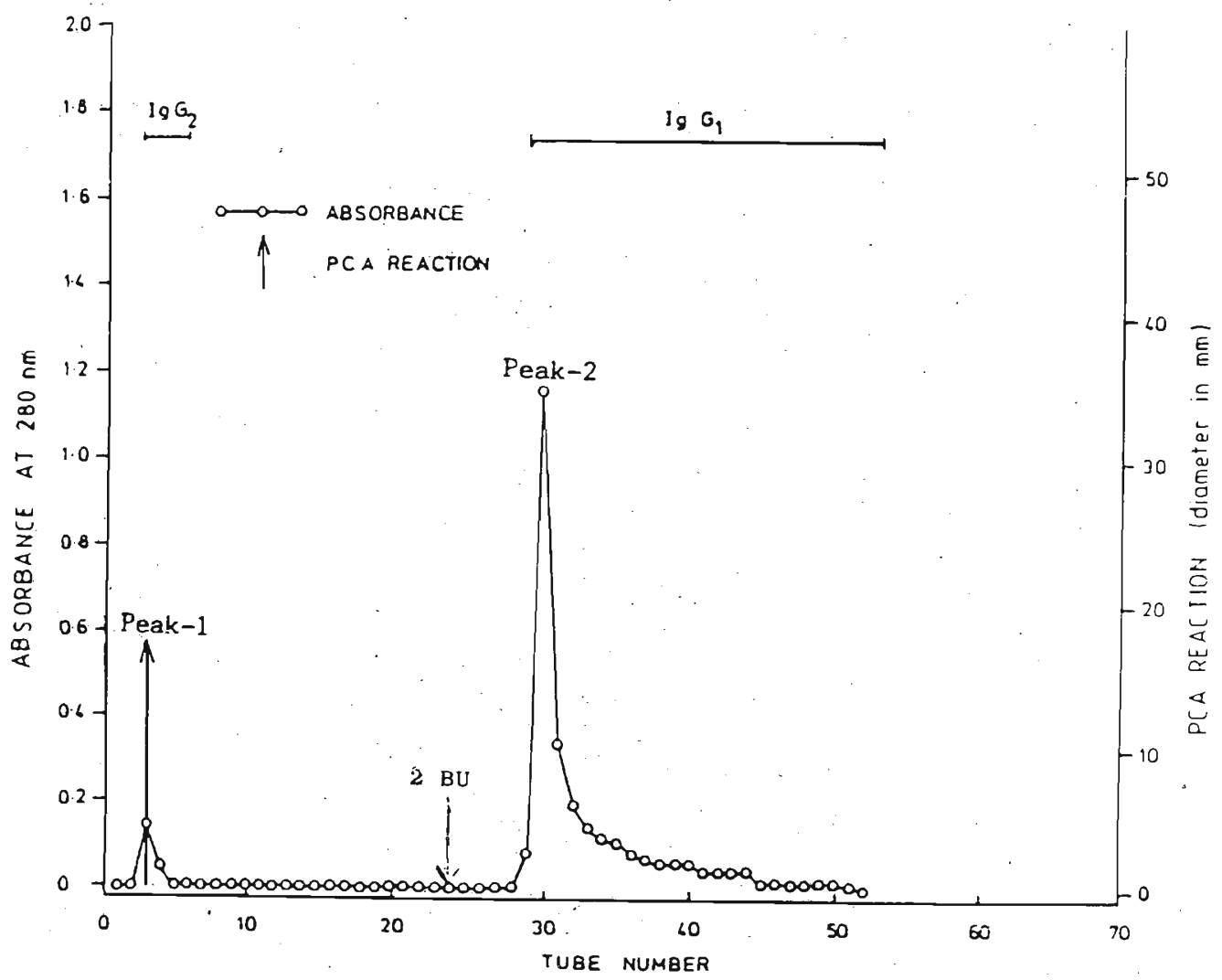

Figure 6. Ion exchange chromatography on DEAE-A-25 'Sephadex' of IgG's from a sample constituted by concentrating the bulked eluates from the second peak of 'Sephadex' G-200 gel-filtration (Figure 2). Peak-1 of Figure 6 was eluted with the starting buffer $0.056 \mathrm{M}$ Tris - hydrochloride $(\mathrm{pH} \mathrm{8.6)}$ ) and peak-2 was eluted with the second buffer $0.056 \mathrm{M}$ Tris-hydrochloride in $0.1 \mathrm{M}$ sodium chloride ( $\mathrm{pH} \mathrm{8.6)}$. Six $\mathrm{ml}$ amounts of eluates were collected; DEAE-A-25 was washed with three column volumes of the initial buffer before the second buffer was applied; The second buffer was applied after the 23 rd eluate was collected. 


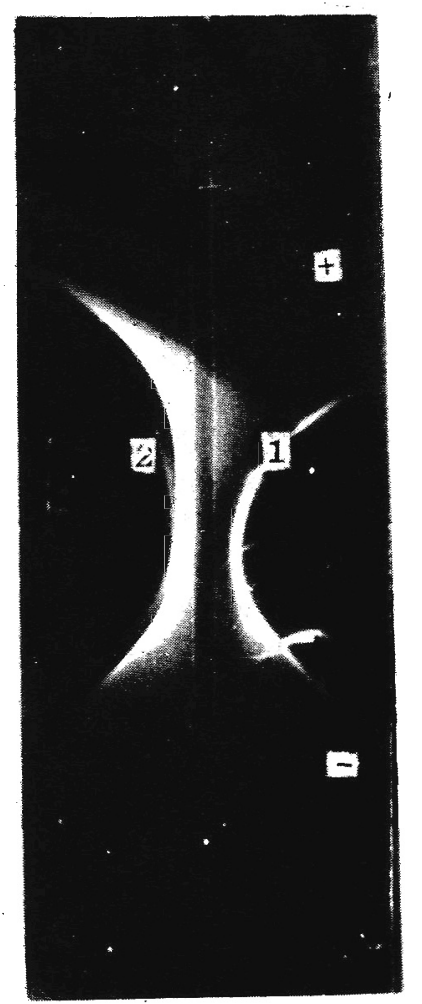

Figure 7. Immunoelectrophoresis on the concentrated pooled eluates from the peaks 1 and 2 (Figure 6). Well 1 , slow IgG $\left(\operatorname{IgG}_{2}\right.$ ) eluted in the peak-1; Well 2 , fast IgG $\left(\operatorname{IgG}_{2}\right)$ eluted in the peak-2; The precipitin reaction was elicited with rabbit antibuffalo globulin serum in the longitudinal trough; $\mathrm{IgG}_{2}$ shows little movement towards the anode whereas $\mathrm{IgG}_{1}$ shows a considerable movement towards the anode.

\subsection{Action of $0.2 \mathrm{M} \mathrm{2-mercaptoethanol} \mathrm{(2-ME)} \mathrm{on} \mathrm{the} \mathrm{antibody} \mathrm{activity} \mathrm{of}$ the fractions}

It was observed (Figures 3,4 ) that most of the IgM was eluted along with the probable $\alpha_{2}$-macroglobulin in the ascending limb of peak-1, whereas with the fraction 2 of the peak which follow the ascending limb, the IgM and the probable $\alpha_{2}$-macroglobulins were eluted with a minimum of two other proteins which have not been identified in this study. Therefore immunoelectrophoresis was carried out only on fraction-1 of 'Sephadex' G-200 gelfiltration subjected to the 2-ME reduction. The band which migrated to the cathode starting from the anode side of the well disappeared on 2-ME treatment. But the band starting from the cathodal side with anodal migration was not affected. Thus the protein representing this distinct and thick band was not affected by 2-ME reduction. It is thought that this protein is an $\alpha_{2}-$ macroglobulin type. 


\subsection{Distribution of antibodies}

Gel precipitins test (GPT) of fractions against infective egg antigen of T. vitulorum (TVE) and in vitro larval precipitin reaction (IVP)

The GPT were located mostly in the fractions constituting the ascending limbs and summits of the peak-2 of 'Sephadex' G-200 gel filtration chromatograms and in the peak-2 of the chromatogram from DEAE-A-25. This indicated that the GPT were present in the $\operatorname{IgG}_{1}$. Likewise the IVP reaction was confined to the ascending and descending limbs and the summit of the peak-2 of 'Sephadex' G-200 gel filtration chromatogram and peak -2 of $\mathrm{DEAE}-\mathrm{A}-25$ 'Sephadex' chromatogram confirming that the GPT and IVP activity were confined largely to the $\mathrm{IgG}_{1}$ not to $\mathrm{IgG}_{2}$.

The GPT and IVP activities were detected only from fractions of sera collected from two weeks after the experimental infection of buffalo calves on day 160 and not from the sera collected during the prepatent and patent phases.

\subsection{Enzyme linked immunosorbent assay (ELISA)}

The ELISA activity was distributed throughout in the peaks -1 and -2 , the trough between these peaks and in the trough following peak-2. There was little or no quantitative difference in the activities of the fractions of peaks-1 and -2 which consisted largely of IgM and IgG. The peak -3 showed only little activity in the early part of the ascending limb (Figures 1 and 2). The activities of the troughs between peaks -1 and -2 and those of the trough following peak -2 were relatively low.

The serum which was collected after 24 hours of birth showed a slightly different type of antibody distribution in that even the troughs between peaks -1 and -2 revealed a considerable amount of ELISA activity. The reason for this behaviour is not known. The ELISA activity of the fractions from the troughs fell to very low levels by day 7 . In general the distribution of ELISA activity in the fractions of sera collected in the course of prepatent, patent and four to eight weeks after an experimental infection did not show any noticeable difference.

\subsection{Passive cutaneous anaphylaxis (PCA) reaction on fractions of 'Sephadex' G-200 gel filtration}

The test could be carried out on the fractions of three serum samples each collected during the patent and post-experimental phases of the infection because only two Ayreshire calves reared free of helminth infections were available for skin sensitization. Only the fractions from 'Sephadex' G-200 filtration were used. The PCA activity of the sera during the patent phase of T. vitulorum infection (6-8 weeks of birth) was mainly located in the ascending part of peak-2. The ascending and descending limbs of the small 
peak preceding the peak -2 also showed a considerable activity (Figure 1; Fractions 4 and 5). But the activity of the sera collected after 1-5 weeks after experimental infection. was confined to two small peaks $(1 \mathrm{a} ; 1 \mathrm{~b})$ preceding peak-2 (Figure 2; Fractions 5 and 6). In addition weak reactions were noted in the fractions from descending limb of the peak-2 and the trough following the same peak. The number of serum samples and their fractions used to elicit the PCA reactions is inadequate to make a reasonable interpretation of the data. Further PCA studies were carried out using the $\operatorname{IgG}_{1}$ and $\operatorname{IgG}_{2}$ fractions isolated from post-experimental infection sera by DEAE-A-25 'Sephadex' fractionation, and it was noted that the reaction was condined to the breakthrough peak which consisted largely of $\operatorname{IgG}_{2}$ (Figure 6).

3.9 Cross reactivity of the fractions constituting the area preceding the peak 2 against sheep antihuman IgE (6-chain) specific serum

No cross reaction was noted in agar diffusion precipitin test when the fractions (Figure 2) suspected to contain the IgE type of antibody (two small peaks $1 \mathrm{a}$ and $1 \mathrm{~b}$ preceding the peak-2) were diffused against sheep antihuman IgE (6-chain) specific sera.

\section{Discussion}

Upto now it appears that little or no systematic attempt has been made on the characterization of buffalo immunoglobulins and a considerable amount of work is necessary to characterize these immunoglobulins and compare them with those of the other related species of the bovidae.

The results of these studies clearly showed that the buffalo immunoglobulins namely IgG and IgM cross react with the antibodies to homologous immunoglobulins of cattle (Figures 4 and 5). It is therefore evident that the antisera prepared against the heavy chains ( $\gamma$ and $\mu$ ) of the cattle can be used in serodiagnosis of buffalo immunoglobulins. Immunoelectrophoretic studies on the fractions concentrated from different parts of the elution peaks from 'Sephadex' G-200 gel-filtration confirmed similarities of the pattern of precipitin arcs of buffalo IgG and IgM to those of similar immunoglobulin classes in other domestic animals and in man (Figure 3). The buffalo IgM which was eluted in the first peak and the trough following the first peak cross-reacted with rabbit antibovine IgM ( $\mu$-chain) specific sera confirming that it was the immunoglobulin type IgM. This was again confirmed by its sensitivity to 2-mercaptoethanol treatment. It was noted also that with the eluates of the peak-1 of the 'Sephadex' gel filtration chromatogram the IgM was eluted along with another protein possibly an $\alpha_{2}-$ macroglobulin type. This protein was well defined in the ascending limb of the peak-1 of gel filtered sera collected on days 1 and 7 of birth. And this was confirmed by the similar precipitin pattern observed when this fraction was subjected to immunoelectrophoresis along with neonate sera of a buffalo calf which is rich in $\alpha_{2}$ - macroglobulin. The contamination of the 
$\ddot{\alpha_{2}}$ - macroglobulin with IgM of bovine sera is the main problem in purification of IgM. ${ }^{9}$

The reaginic antibody activity however showed a distribution mostly in the area immediately preceding the peak-2. Further examination of the $\operatorname{IgG}_{1}$ and $\operatorname{IgG}_{2}$ subclasses revealed that $\operatorname{IgG}_{2}$ had a considerable reaginic activity. Earlier studies of the reaginic antibodies in the sera of goats sensitized with human gamma globulin has shown ${ }^{2}$ that the activity was confined to the $\operatorname{IgG}_{2}$ and further it was susceptible to the action of heat and 2mercaptoethanol reduction as was the IgE of man. Further these studies 22 have. shown also that only $\operatorname{IgG}_{1}$. was active in haemolysis in complement fixation, and this subclass induced PCA and passive Arthus reaction in heterologous species whereas the $\mathrm{IgG}_{2}$ lacked haemolytic and complement fixation ability but induced homologous PCA.

The results of PCA tests on fractions prepared from buffalo sera revealed the presence of a reaginic antibody similar to human $\operatorname{Ig} E$ type which was eluted also preceding peak-2 in 'Sephadex' G-200 gel filtration. Halliwell, Schwartzman, Montgomery and Rocky ${ }^{10}$ found that in canine sera the IgE activity was confined also to the area preceding the 7S (peak2 ) and to half of the ascending slope of this peak from 'Sephadex' G-200 gel filtration and that the highest IgE activity was confined to the commencement of the $7 \mathrm{~S}$ peak (second peak). In the course of natural patent infection of buffalo calves the reaginic antibody activity apparently similar in its action to $\mathrm{IgE}$ was low when compared with that elicited by similar $\mathrm{G}-200$ filtration fractions of sera in the course of the post-experimental infection. But the undiluted sera of the patent phase of natural infection showed a marked PCA reaction. On the other hand the neat sera of the post-experimental infection either showed weak or no PCA reactions. This may be referable to masking of $\mathrm{IgE}$ - like antibody activity in the presence of $\operatorname{IgG}_{1}$ or the competition of the antibodies for mast cell receptors. Similar type of masking IgE in the presence of IgG1 has been described previously $6,11,19$ in mice where the homologous PCA activity is confined to IgG $_{1}$ subclass. There is no information on the receptor sites of the buffalo $\operatorname{IgG}_{2}$ and $\operatorname{IgE}$ like antibodies. Therefore more studies are needed on these lines. Further in this study the fractions from 'Sephadex' G-200 filtration were used and the chances of contamination of IgE and $\operatorname{IgG}_{2}$ types in a fraction can be assumed to be less likely for the masking or competition of antibodies to occur (unlike with the case of unfractionated sera). Therefore the observed values of the PCA reactions can be assumed to be proportional to the actual level of the each homocytotropic antibody in the sera.

The antigenic cross reaction of reaginic antibodies (IgE) was described in several species. Sharing of common antigenic determinants of canine and human IgE in reverse cutaneous anaphylaxis using antihuman IgE has been noted. ${ }^{10}$ In this study however an attempt to identify a reaginic antibody of buffalo sera by means of gel-diffusion reactions using sheep antihuman IgE (G-chain) specific sera was not successful. Likewise cross reactions 
between rabbit or sheep antihuman $\operatorname{IgE}$ antibodies with the bovine $\operatorname{Ig} \mathrm{E}$ could not be demonstrated. On the other hand Nielsen ${ }^{23}$ recorded strong cross reactions of cow, goat, pig and rabbit sera against sheep antihuman IgE specific sera by radial immunodiffusion and by the ability of the reaginic immunoglobulin to bind to rat mast cells. Further work is necessary for the identification of reaginic type of antibodies in the buffalo sera.

\section{Acknowledgement}

The authors are grateful to. NARESA and SAREC for Grant SAREC/9/BF/04. The assistance of IAEA at the initial phase of the study is acknowledged. The authors acknowledge with pleasure the technical assistance of Mr. W. G. Senaratne and Miss $M$. Herath for.the typing assistance.

\section{References}

1. AMERASINGHE, P., MASOODI, M.A., SIVANATHAN,, S.. GUNAWARDENA, V.K. \& FERNANDO, S.T. (1974) : Immunological response of pregnant swamp and murrah buffalo cows and calves to Toxocara vitulorum infection. Proceedings of the Final Research Co-ordination Meeting Joint FAO/TAEA Division, 30th Jan. to 3rd Feb. 1984, 161-170.

BLOCH, K., MORSE, H.C. \& AUSTEN, K.F. (1968) Biologic properties of rat antibodies. 1. antigen-binding by four classes of anti-DNP antibodies. J. Immunology $101: 650-663$.

3. BUTLER, J.E. (1969) Bovine immunoglobulins, a review. J. Dairy Sci. 52 : 1895-1909.

4. BUTLER, J.E. (1971) Review of the bovine immunoglobulins. In Symposium : Bovine immune system, Session 1. Characterisites of bovine immunoglobulins and related molecules. J. Dairy Sci. 54 : 1315.

5. DUFFUS, W.P.H. \& FRANKS, D. (1981) Interaction in vitro between bovine immunoglobulin and juvenile Fasciola bepatica. Parasitology 82 : 1-10.

6. FAHEY, J.L., WUNDERLICH J. \& MISHELL, R. (1964) The immunogiobulins of mice. 11. Two subclasses of mouse $7 \mathrm{~S} \mathrm{Y}_{2}$-globulins: $\mathrm{Y}_{2 \mathrm{a}}$-globulins. J. Exp. Med. $120: 243-251$.

7. FERNANDO, S.T. \& SOVLSBY, E.J.L. (1974) Immunoglobilin class of antibodies in monkeys infected with Toxocara canis. J. Comp. Path. 84 : 569-576.

8. FERNANDO, S.T., VASUDEVAN, B., HAMZA, N.H.M., PANDITHAGUNAWARDANA I.K.T. \& SAMERASINGHE, H.J. (1970) Precipitin reactions in monkeys (Macaca sinica) experimentally infected with Toxocara cants, and in children with visceral larva migrans syndrome. J. Comp. Path. $80: 407-414$.

9. FEY, H., PFISTER, H., MESSERLI, J., STURZENEGGER, N. \& GROLIMUND, F. (1976) Methods of isolation, purification and quantitation of bovine immunoglobulins (A technical review), Zentralblatt fur Veterinarmedizin Reibe B 23 : 269-300.

10. HALWELL, R.E.W., SCHWARTZMAN, R.M., MONTGOMERY, P.G. \& ROCKEY, J.H. (1972) Physicochemical properties of canine IgE. Transplantation Proceedings 7 : 537-543.

11. HAMMER, D.K., KICKHOFEN, B. \& SCHMID, T. (1971) Detection of homocytotropic antibody associated with a unique immunoglobulin class in the bovine species. European J. Immunology 1 : 249-257. 
12. HEIDELBERGER, M. (1946) The activating effect of magnesium and other cations on the haemolytic function of complement. J. Exp. Med. 84 : 535-548.

13. HOGARTH-SCOTT, R.S. (1969) Homocytotropic antibody in sheep. Immunology 16 : 543-548.

14. KABAT, E.A. \& MAYER, M.M. (1961) Experimental Immunochemistry Charles C. Thomas, Springfield Illinois, U.S.A.

15. KICKHOFEN, B., HAMMER, D.K. \& SCHEEL, D. (1968) Isolation and characterization of G type immunoglobulins from bovine serum and colostrum. Hoppe-Seyler's Zeitschrift fur Physiologische Chemie. 349 : 1755-1773.

16. KULKARNI, B.A., RAO, S.S. \& RINDANI, T.N. (1973) Immunoglobulins of the Indian buffaloes. Indian J. Biochem. \& Biophysics $10: 216-219$.

17. KULKARNI, B.A., RAO, S.S. \& RINDANI, T.N. (1973) Transfer of colostral immunoglobulins and tetanus antibodies from the buffalo to neonatal calves. Indian J. Biochem. \& Biophysics 11 : 2199-303.

18. KULKARNI, B.A., RAY, S.S. \& RINDANI, T.N. (1975) Antigenic cross reactions between immunoglobulins of some farm animals and man. Indian J. Biochem. \& Biopbysics 12 : 192193.

19. LEHRER, S.B. (1977) Role of mouse IgG and IgE homocytotropic antibodies in passive cutaneous anaphylaxis. Immunology $32: 507-511$.

20. LOWRY, O.H., ROSEBROUGH, N.J., FARR, A.L. \& RANDALL, R.J. (1951) Protein measurement with Folin phenol reagent. J. Biol. Chem. $193: 265-275$.

21. MAYER, M.M. OSLER, A.G., HELDELBERGER, M. \& BIER, O.G. (1946) The activating effect of magnesium and other cations of the haemolytic function of complement. J. Exp. Med. 84 : 535-548.

22. MICUSAN, V.V. \& BORDUAS, A.G. (1977) Biological properties of goat immunoglobulins C.Immunology 32 : 373-381.

23. NIELSEN, J.T. (1969) Gel-filtration and disc electrophoresis of somatic extracts and excretions and secretions of Haemonchus contortus larvae. Experimental Parasitology $25: 131-141$.

24. OVARY, Z. (1952) Cutaneous anaphylaxis in the albino rat. International Archives of Allergy and Applied Immunology 3 : 293, 